\title{
PANDEMIA DE COVID-19, PROJETO COLONIAL E INFLEXÕES ANTICOLONIAIS NA EDUCAÇÃO ESCOLAR
}

\author{
Lúcia Helena Alvarez Leite \\ Universidade Federal de Minas Gerais - UFMG \\ Bárbara Bruna Moreira Ramalho \\ Rede Municipal de Educação da Prefeitura Municipal de Belo Horizonte \\ Paulo Felipe Lopes de Carvalho \\ Rede Estadual de Educação do Estado de Minas Gerais
}

\begin{abstract}
Resumo
A pandemia de COVID-19 intensificou, por vezes atribuiu novos delineamentos, mas, sobretudo, desnudou dinâmicas sociais perversas historicamente produzidas pelo sistema-mundo Moderno de matriz colonial. Sob este entendimento, e tomando como ponto de partida as narrativas presentes em textos jornalísticos recentemente publicados, nos propomos a analisar neste ensaio a vigência do projeto colonial na educação escolar e, especialmente, as conformações por ele assumidas neste momento histórico marcado pelo distanciamento social. Em contrapartida, mais do que a realização da denúncia do estado de coisas, o presente artigo se propõe também a, por meio da análise de experiências em curso, tornar explícitas alternativas anticoloniais de organização da sociedade e, nela, da educação escolar. As discussões realizadas nos permitem concluir que, em decorrência da pandemia, a educação escolar encontra-se, de maneira mais explícita, diante de uma de uma encruzilhada na qual de um lado está a possibilidade do emprego de esforços com vistas ao reajustamento à injusta normalidade e, de outro, a proposição de Outros projetos educativos.
\end{abstract}

Palavras-chave: Colonialidade da educação, Educação anticolonial, Covid-19 e educação.

\begin{abstract}
The COVID-19 pandemic has intensified, sometimes assigning new outlines, but, mainly, it exposed the perverse social dynamics historically produced by the modern colonial world system. Under this understanding and taking as a starting point the narratives present in newspapers' news recently published, we propose to analyze in this essay the permanence of the colonial project in school education and, especially, the conformations assumed by it at this historical moment of social distancing. In contrast, more than just denouncing the state of affairs, this article also proposes to show, through an analysis of ongoing experiences, anti-colonial alternatives for the organization of society and, in it, in school education. The discussions carried out allow us to conclude that, because of the pandemic, school education is explicitly been faced by a crossroad where, on the one hand, there is the possibility of using efforts for readjust to an unjust normality and, on the other, the proposition of Other educational projects.
\end{abstract}

Keywords: Coloniality of education, Anti-colonial Education, Covid-19 and education. 


\section{Coronavírus e a vigência do projeto colonial na sociedade}

Segundo dados divulgados pelo Ministério da Saúde (Brasil, 2020a), o primeiro caso de COVID-19 no Brasil foi oficialmente registrado no dia 25 de fevereiro de 2020. A vítima era um homem de 61 anos, residente da maior metrópole da América Latina, São Paulo, que havia retornado de uma viagem pela região de Lombardia, na Itália. Estando hoje curado, à época, o paciente foi atendido no Hospital Israelita Albert Einstein, instituição amplamente conhecida pela qualidade dos serviços prestados na área médica e, especialmente, pelo atendimento à elite política e econômica do país. Este, entre outros casos, ilustra o fato de que o coronavírus, em um primeiro momento, incidiu sobre o conjunto mais rico da população brasileira. O que é por muitos interpretado como uma espécie de "sorte", já que essas vidas, em uma sociedade colonial, capitalista, racista e patriarcal como a nossa promovem maior comoção do que as de $\operatorname{Outros}^{1}$ carregando, assim, maior capacidade de mobilização em torno do combate à doença.

Cerca de duas semanas após a ocorrência do primeiro caso no Brasil, em 11 de março de 2020, a Organização Mundial da Saúde (OMS) identificaria a ampla disseminação da doença pelo mundo, passando, assim, a configurá-la como uma enfermidade pandêmica. A partir deste estado de coisas, não tardou a emergência da narrativa - textual ou implicitamente difundida pelo poder público e a imprensa - de que do Norte ao Sul, geográfico ou global (Santos; Meneses, 2010), estávamos igualmente vulneráveis ao inimigo invisível. A morte de Cleonice Gonçalves, trabalhadora doméstica na cidade do Rio de Janeiro que, sem conhecimento prévio, foi exposta ao vírus por meio do contato com a sua empregadora (já recuperada) - que, tal como no outro caso, havia testado positivo para a doença após uma viagem de férias na Itália (Costa, 2020) -, entre outros muitos exemplos que se seguiram, contestam essa narrativa.

Passado mais de um semestre do registro do primeiro caso de COVID-19 na província de Wuhan, na China, e alguns meses da sua presença no Brasil, a empiria tem demonstrado, os intelectuais, analisado e os órgãos de imprensa, difundido, que o discurso universalista abstrato é falacioso.

Embora os Estados Unidos da América, maior potência econômica mundial, tenha se tornado o epicentro da doença, acumulando ainda em julho de 2020, quando este ensaio foi escrito, o maior número de mortes registrados no período, os casos vêm crescendo ainda com maior velocidade no Brasil. Além disso, é preciso ter em vista que, por aqui, a curva de letalidade tem sido ilusoriamente "achatada" pela orientação genocida e pela incompetência do presidente da república que se recusa a elaborar e colocar em curso planos estruturados de detecção e combate à doença, mas também porque os Estados Unidos da América piratearam os testes que havíamos comprado da China ${ }^{2}$.

Nesse sentido, ao que parece, em nossa sociedade Moderna - e, em princípio, civilizada -, naturalizado está o imaginário de que as vidas estadunidenses e/ou de outros países chamados "centrais" valham mais do que as brasileiras. Nesta pandemia, aparentemente, os latinos podem morrer de "Síndrome Respiratória Grave" para que as famílias estadunidenses conhecerem as exatas razões da perda de seus entes. 
Também contestando a narrativa universalista, a esta altura já sabemos que a letalidade da doença é maior entre os pobres e pretos (Núcleo de Operação e Inteligência em Saúde, 2020), como também temos conhecimento de que as multiformes consequências do COVID19 são mais intensas entre as mulheres (Estrela, 2020; Marques, 2020). Além disso, uma vez mais na nossa história temos testemunhado o descaso do poder público com os povos indígenas frente a uma epidemia (Pontes et al., 2020).

Desse modo é, de fato, possível que a humanidade esteja enfrentando o mesmo mar revolto, como sugerem alguns. Havemos de admitir, entretanto, que neste desastre, há aqueles que se encontram abrigados em grandes navios, outros em pequenas embarcações, e, ainda, os que, mergulhados nas violentas águas salgadas, não portam sequer um colete salva-vidas. Nesse sentido, ratificamos a afirmação de Boaventura de Sousa Santos de que

[...] as pandemias não matam tão indiscriminadamente quanto se julga. Evidente que são menos discriminatórias que outras violências cometidas na nossa sociedade contra trabalhadores empobrecidos, mulheres, trabalhadores precários, negros, indígenas, imigrantes, refugiados, sem abrigo, camponeses, idosos, etc. Mas discriminam tanto no que respeita à sua prevenção, como à sua expansão e mitigação (Santos, 2020, p. 23).

Diante desta dura realidade, não nos furtamos à interpretação de que, embora estejamos vivendo e testemunhando uma experiência inegavelmente grave, não estamos exatamente frente a uma nova forma de funcionamento do sistema-mundo Moderno (Wallerstein, 1974). O colonialismo e, portanto, o estabelecimento de hierarquias a partir de critérios raciais e de gênero, com vistas à perpetuação ou - como defendem alguns a respeito do século XXI - à sobrevivência do capitalismo é, no contexto da pandemia, como antes dela, a matriz orientadora de funcionamento da sociedade Moderna. Na crise sanitária de 2020, a novidade seja talvez - mas não para toda a população mundial e aqui nos lembramos, por exemplo, da situação das pessoas refugiadas, daquelas que vivem em favelas, das que morrem vítimas de doenças negligenciadas (Santos, 2020) - a intensidade e as roupagens assumidas por este projeto de dominação.

Ampliamos esta interpretação para o cenário educacional. Conforme buscaremos refletir nas próximas páginas, os dilemas verificados no âmbito da educação escolar, entre os quais destacamos o reconhecimento subalterno de determinadas identidades; a exclusão e/ou a inclusão subalterna de determinados sujeitos coletivos na escola; o imperativo da racionalidade Moderna eurocentrada; e a associação da educação hegemônica à reprodução do sistema-mundo vigente, podem ter assumido novos delineamentos no contexto da pandemia de COVID-19. Eles não são, entretanto, inaugurados neste momento histórico. Ao contrário disso, remetem à herança colonial na educação escolar.

Para o desenvolvimento deste argumento no presente ensaio mobilizaremos publicações jornalísticas relativas à educação no contexto da pandemia e estabeleceremos especial interlocução com três publicações realizadas em uma mesma edição do jornal Folha de São Paulo em maio de 2020. Assim, com a finalidade de demonstrar que o discurso assumido 
pelo referido veículo de comunicação converge com aqueles mobilizados por outros atores da mídia de amplo alcance, e buscando explicitar que se trata de uma narrativa que se sustenta no tempo, ao longo do texto referenciaremos outras publicações do jornalismo impresso que nos últimos meses tematizaram a escola a partir do isolamento social imposto pela COVID19.

\section{Coronavírus e a vigência do projeto colonial na educação escolar}

No dia 14 de maio de 2020, o jornal Folha de São Paulo divulgou uma matéria jornalística de capa, uma entrevista e uma coluna que versavam sobre o tema da educação escolar brasileira no contexto da pandemia de coronavírus. No primeiro texto, há uma espécie de denúncia quanto à ineficácia da adoção do ensino remoto tendo em vista as dificuldades de acesso dos estudantes do Estado de São Paulo à internet e a suportes como telefone celular, computador e televisão. Nessa reportagem também foram feitas referências às estratégias empregadas por redes públicas de várias localidades do país com vistas a mitigar - para usar a palavra que virou moda no contexto da pandemia - a baixa participação dos estudantes nas práticas de educação não presencial.

Já no texto opinativo, a colunista Laura Mattos é enfática em anunciar o "novo normal" - outro termo exaustivamente utilizado nos últimos meses - para a educação. Para ela, o ensino não presencial constitui-se um desafio a ser encarado pela sociedade com vistas a desfrutar, em um futuro próximo, de seus inúmeros potenciais. Desse modo, nas palavras da escritora,

[...] tudo isso, que agora São Paulo e outros estados correm para desenvolver, valerá ouro na pós-pandemia [...] Imagine, por exemplo, que todos os alunos do país possam ter aulas com os melhores mestres dos mais variados temas em conexão com o material didático e com o professor da sala treinado para intermediar e tirar dúvidas sobre as apresentações gravadas (Mattos, 2020a, n.p.).

Por fim, além de apresentar a "crise" e de construí-la como uma espécie de "oportunidade", nesta edição do jornal, a "solução" para o dilema da educação no contexto de (pós) pandemia é também apresentada e por ninguém menos do que pelo segundo empresário mais rico do Brasil, segundo os dados da revista estadunidense Forbes: Jorge Paulo Lemann. Na ocasião, o diretor de uma das fundações de maior influência no campo educacional do país, afirmou: "Uma das coisas importantes é o que podemos fazer nessa área de ensino a distância porque essa é a oportunidade grande do momento para ajudar e fazer algo importante para o Brasil no longo prazo" (Martinez-Vargas, 2020, n.p.).

Essas publicações, como outras a elas correlatas que serão aqui referenciadas, remetem aos desafios educacionais "do presente". Mais do que isso, nos permitem refletir sobre o que há, de fato, de inédito nos dilemas enfrentados pela educação no contexto da pandemia e o que se constitui, na verdade, uma reatualização do modo de operação colonial. 
Sob esta perspectiva e, tomando como referência a matéria Menos da metade dos alunos da rede estadual de São Paulo acessa ensino online na quarentena (Pinho, 2020), o nosso primeiro argumento é o de que os sujeitos hoje excluídos da educação escolar em decorrência da ausência de condições de acesso às atividades remotas no contexto da pandemia, tema também abordado por Ximenes et al. (2020), Dolzan (2020) e Idoeta (2020), são os filhos, netos, bisnetos, ou seja, a descendência daqueles que, a partir do reconhecimento negativo de suas identidades, foram historicamente alijados do acesso à escola ou, quando muito, a quem endereçou-se um acesso subalterno à educação escolar.

No caso brasileiro, os povos indígenas, as pessoas negras, as mulheres - e, portanto, aqueles que não compartilhavam da identidade padrão sintetizada na insígnia "homembranco-heterossexual-europeu" - foram, desde a educação dos jesuítas, e, portanto, desde a origem da educação formal no país, representados enquanto bárbaros, incivilizados e primitivos. Formulação que sustentou a narrativa da incapacidade de aprendizagem por esses sujeitos, legitimando, por sua vez, a sua completa exclusão dos processos educativos formais e/ou o endereçamento de práticas educacionais a eles. Sob essa perspectiva, tem-se no período colonial o direcionamento de práticas de evangelização e alfabetização aos povos indígenas, o ensino de artes e ofícios às pessoas escravizadas trazidas de África, e, finalmente, a reprodução dos conteúdos e práticas dos colégios jesuíticos europeus para os filhos dos colonizadores (Veiga, 2007 e Fonseca, 2006).

No Brasil Império, os grupos escolares foram propostos pelas elites enquanto uma estratégia de organização e coesão da sociedade. No entanto, a não adesão deste grupo à instituição por ele próprio formulada e defendida torna notável quais eram, naquele contexto, os sujeitos compreendidos como adequados a serem submetidos aos processos educativos formais: a população pobre, negra e mestiça. Nesse sentido, em detrimento do exercício de um potencial emancipatório, conforme bem pontua Veiga (2007), no período Imperial, a educação pública institucionalizada acabou por referendar a representação subalterna dos já inferiorizados.

No contexto Republicano a educação escolar é assumida enquanto estratégia de elevação dos sujeitos Outros à condição de exercício da cidadania. Nesse sentido, ela pode ser interpretada como uma espécie de dever ao qual os "incivilizados" devem se submeter sob a promessa de transformarem-se em "sujeitos de direitos" ou, em outras palavras, alcançarem a Moderna condição de "cidadãos da república". Assim, conforme expõe Arroyo (2010, p. 33), paradoxalmente, na República, "o mesmo discurso que enfatiza a liberdade e a cidadania enfatiza a necessidade da educação para a liberdade e para a cidadania". Concepção que, entre outras inúmeras práticas, orientou o condicionamento do direito ao voto à capacidade de leitura e escrita das pessoas até o ano de 1985 em nosso país.

Se, como vimos, do contexto colonial ao republicano a educação hegemônica assume, alinhada aos parâmetros coloniais, a narrativa do devir, é apenas em 1934 (Brasil, 2020b) que o acesso a ela figura como um direito constitucional. Ou seja, até então, a educação oficial era pronunciada como condição de elevação das identidades a determinados estágios de desenvolvimento, mas - e aqui reside uma outra contradição - aos sujeitos Outros, o acesso à ela foi interditado por quase cinco séculos. 
Será apenas recentemente, com a Constituição de 1988, que todos os brasileiros - os quais, aliás, somente a partir deste período começam a gozar indistintamente da condição de cidadãos (Souza, 2003) - passam a ter o direito de frequentar as salas de aula de Ensino Fundamental. A seguridade de acesso à Educação Infantil e ao Ensino Médio, não nos esqueçamos, data apenas de 2009 (Brasil, 2009).

Ademais, é imperativo pontuar que, embora tenhamos alcançado a quase universalização do acesso ao Ensino Fundamental, ainda na segunda década do século XXI, cerca de 1,3 milhão de crianças e adolescentes brasileiros com idades entre 4 e 17 anos - cujas identidades sabemos de partida - não acessam hoje o direito à Educação Básica (Brasil, 2018a). Outra face perversa da exclusão, essa mais permanentemente denunciada no campo educacional, são os altíssimos índices de evasão e abandono escolar verificados entre os anos finais do Ensino Fundamental e do Ensino Médio. Além disso, ainda que no início deste século tenhamos logrado importantes avanços no que diz respeito ao acesso das pessoas negras, indígenas, camponesas e pobres ao Ensino Superior (Instituto Nacional de Estudos e Pesquisas Educacionais Anísio Teixeira, 2018), tendo em vista o percentual da população brasileira que compartilha destas identidades, esses sujeitos encontram-se ainda subrepresentados neste nível do ensino.

Sob essa perspectiva não há dúvidas de que o dilema das desigualdades de acesso ao ensino não presencial nesse momento histórico cujo distanciamento social se faz necessário deva ser amplamente discutido pelos diversos atores da sociedade, incluindo-se neles os veículos de comunicação. O debate se faz imperativo, entretanto, não pelo ineditismo da questão, já que ele é inverídico. Ao contrário, as discussões devem ser realizadas à luz da convergência entre essas inequidades contemporâneas e a perversa matriz Moderna/colonial, excludente e subalternizadora, constitutiva da educação escolar brasileira.

Outra dimensão presente nos textos publicados pela Folha de São Paulo e que nos parece relevante de ser centralizada no debate acerca da educação no contexto da pandemia e seus vínculos com o projeto colonial é um certo otimismo assumido pelo veículo quanto às práticas de Educação a Distância $(\mathrm{EaD})$, Remota ou Síncrona ${ }^{3}$. Essa crença fica bastante evidente na coluna As lições da quarentena para a educação (Mattos, 2020a), mas é também compartilhada por colunistas de outros jornais impressos de circulação nacional (Diniz, 2020; Soares, 2020 e Gomes, 2020).

Em nosso entendimento, o entusiasmo em relação a essa modalidades de ensino se assenta no imaginário hegemônico de que, asseguradas as condições mínimas e, portanto, a materialidade necessária (computadores, tablets, celulares, internet etc.), a educação não presencial teria não apenas o potencial de efetivar os processos de ensino-aprendizagem para todas as pessoas, como também o de tornar o currículo escolar mais justo, já que promoveria as mesmas oportunidades de aprendizagem - ou as mesmas aulas - a distintos estudantes. Essa crença se apoia em uma concepção de currículo que, como destaca Saviani, "[...] é entendido comumente como a relação das disciplinas que compõem um curso ou a relação dos assuntos que constituem uma disciplina, no que ele coincide com o termo programa" (Saviani, 2016, p. 54). Uma convicção restrita, superficial, conservadora que é própria do 
projeto colonial e que se faz presente na sociedade e no contexto educacional brasileiro muito antes da chegada da pandemia de 2020.

No desenvolvimento desse argumento faz-se necessário esclarecer, em primeiro lugar, que o projeto colonial se desenvolveu sob uma estratégia de dupla incidência: de um lado, tem-se a imposição da identidade, do modo de organização social, e também das culturas e saberes do colonizador; e, de outro, a aniquilação ou deslegitimação dos atributos dos colonizados. Este mecanismo denominado por Mignolo (2003) como "diferença colonial” é, portanto, simultaneamente responsável pela supressão das formas não hegemônicas de saber (Santos, 2007) e pela representação dos conhecimentos referenciados na Europa como os únicos existentes, suficientes para compreensão e produção do mundo e, por isso, "Modernos" e "universais".

Por meio da formulação das noções de Norte e Sul Global, Santos e Meneses (2010) nos ajudam a compreender a persistência deste modo colonial de operação nos dias de hoje. No âmbito de sua teoria, As Epistemologias do Sul, tais termos não designam exatamente localizações geográficas, mas espaços-tempo político, social e cultural que sobreviveram à repartição do mundo entre Espanha e Portugal e, portanto, à convenção da Linha da Amizade. Em outras palavras, sob a ótica destes autores, o Norte designa os atores sociais hegemônicos, entre os quais encontram-se não apenas, mas também, parte dos países da Europa e sua epistemologia "Moderna". Já o Sul designaria os sujeitos individuais ou coletivos, seus saberes e culturas, histórica e contemporaneamente subalternizados. Entre Norte e Sul, defendem os autores, há um enorme abismo - as linhas abissais - que tornaram antes, mas também tornam hoje, impossível a emergência de saberes diversos e horizontalmente comunicantes.

É sob o imaginário da legitimidade, suficiência e do caráter universalista de um conjunto de saberes que, embora sejam provincianos - já que referenciados em apenas uma parcela da sociedade, o Norte Global - e derivados de epistemicídios (Santos, 2007) que a educação escolar hegemônica se desenvolve. E isto, conforme nos lembra o discurso do então primeiro ministro de Granada, Maurice Ruper Bishop registrado no livro Mulheres, cultura e política de Ângela Davis (2016, p. 161), não é obra do acaso.

Talvez o pior crime que o colonialismo cometeu em nosso país, que na verdade cometeu em todas as ex-colônias, seja o sistema educacional. Isso porque aquele sistema era usado para ensinar ao nosso povo uma atitude de ódio a si mesmo, para fazê-lo abandonar nossa história, nossa cultura, nossos valores. Para fazê-lo aceitar os princípios da superioridade branca, destruir nossa confiança, reprimir nossa criatividade, perpetuar em nossa sociedade os privilégios e as diferenças de classe. Os senhores colonialistas perceberam bastante depressa que, se conseguissem que um povo subjugado pensasse como eles, esquecesse sua própria história e sua própria cultura, [...] então eles já teriam concluído o trabalho de nos manter sob dominação e exploração perpétuas.

É a partir desta concepção universalista do conhecimento de matriz Moderna/colonial que a euforia dos veículos de comunicação relativa às práticas de Educação a Distância no 
contexto de (pós) pandemia pode ser compreendida. Na medida em que se considera a existência de um único repertório de conhecimentos, atribui-se a ele o status de suficiência e, claro, assume-se que a apropriação deste se faz igualmente imperativa para todos os sujeitos, é quase óbvia a conclusão de que a solução mais adequada - e, por que não, a mais promissora - para a educação escolar seja a exposição dos diferentes estudantes, em condições consideradas "ótimas", ao conjunto de saberes em causa. Daí a proposição de Mattos (2020a, n.p.) de que “as práticas de EaD poderão 'valer ouro' no futuro próximo da educação".

Mas não nos enganemos. Se no âmbito do distanciamento social a educação não presencial aparece como uma espécie de avatar do projeto Moderno/colonial de educação, não é preciso muito esforço intelectual para localizarmos em nossa história, distante ou recente, outros mecanismos orientados por esta mesma matriz. É o universalismo provinciano fruto do estabelecimento de diferenças coloniais que vimos discutindo que orienta, por exemplo, as inúmeras avaliações sistêmicas - internacionais, nacionais, regionais e locais - a que estudantes e professores são, regularmente, submetidos. E, para não nos estendermos muito nas menções, é também ele que sustenta a elaboração de uma Base Nacional Comum Curricular (Brasil, 2017) no país.

Não é recente, portanto, que, enquanto sociedade, apostamos todas as nossa fichas em um modelo educacional cuja exclusão e o reconhecimento subalterno de sujeitos e saberes é nada menos do que sua matriz. Não o fazemos necessariamente por perversidade, mas pela internalização de uma representação própria do projeto Moderno/colonial e que é decorrente dessa que vimos discutindo até aqui: a formulação da ideia de existência de padrões únicos de estágios de desenvolvimento e a atribuição ao currículo escolar do papel de libertação dos sujeitos e nações de uma condição primitiva e, consequentemente, da elevação desses à uma condição desenvolvida.

O que se ignora nessa narrativa, no entanto, é o fato de que o ininterrupto funcionamento da engrenagem universalista produz profundas exclusões na educação escolar, conforme já abordado neste texto. Mais do que isso, é, ao mesmo tempo, curioso e grave desconsiderarmos que foi justamente o imperativo do desenvolvimento nortecentrado, com o qual o currículo hegemônico cada vez mais se alinha, que nos conduziu ao caos que experimentamos hoje.

Por fim, tomando como referência a entrevista concedida por Jorge Paulo Lemann à Folha de São. Paulo (Martinez-Vargas, 2020), passamos à discussão da hegemonia de um projeto educativo orientado pela (re)produção do sistema-mundo hegemônico em detrimento do fortalecimento de propostas de educação que se proponham à imaginação e à construção de futuros Outros para a sociedade no contexto da pandemia. Nossa compreensão é a de que o protagonismo desses atores é coerente com a concepção hegemônica da educação e do sentido por ela assumido em nossa sociedade Moderna/colonial.

Nessa discussão é preciso, primeiramente, não perder de vista que, conforme analisado pelas teorias anticoloniais, as relações econômicas capitalistas têm emergência no âmbito do projeto de dominação inaugurado entre o final do século XV e o início do século XVI, ou seja, da colonização. Sob essa interpretação, é o estabelecimento de hierarquias entre as 
diferentes identidades que historicamente subsidiam as relações de exploração e, assim, fundamentam a ausência ou acumulação de riquezas por determinados sujeitos coletivos. Interpretação sintetizada por Frantz Fanon (1968, p. 27) no excerto que se segue:

Nas colônias a infraestrutura econômica é igualmente uma superestrutura. A causa é consequência: o indivíduo é rico porque é branco, é branco porque é rico. [...] Não são as fábricas "nem as propriedades nem a conta no banco que caracterizam em primeiro lugar a "classe dirigente'". A espécie dirigente é antes de tudo a que vem de fora, a que não se parece com os autóctones, "os outros".

Além disso, faz-se necessário evocarmos aqui a associação histórica entre a educação formal e a divisão - racial e sexual - do trabalho a que fizemos referência anteriormente. Assim, é verdade que a partir da conquista do direito de amplo acesso à educação escolar no final do século XX soa politicamente incorreto ou, no mínimo, anacrônico defender, como antes fora, inclusive institucionalizado, que pobres, pretos, camponeses, indígenas, mulheres, que foram feitos Outros, não devam frequentar escolas ou que sejam expostos a práticas educativas explicitamente formuladas a partir de seu reconhecimento subalterno. A persistência, entretanto, do alinhamento entre currículo escolar e a segregação econômica constitutiva do projeto Moderno/colonial pode ser verificada, contemporaneamente, entre outros muitos exemplos, na proposição de Reformas de Ensino que sugerem que as camadas populares, em detrimento de acessar conteúdos arrogantemente considerados demasiadamente abstratos - como a Filosofia e à Sociologia ${ }^{4}$-, deveriam se dedicar unicamente à aprendizagem da leitura, escrita, à resolução de problemas matemáticos e à realização trabalhos técnicos e/ou manuais.

Ademais, na sociedade Moderna/colonial contemporânea aparentemente pacificada está, e cada vez mais, a compreensão da educação escolar como um bem de consumo. No contexto neoliberal em que os empregos são escassos e as relações de trabalho precárias, os anos de escolarização - ou nível de qualificação - operam como elementos de distinção entre os sujeitos que dispõem de mão de obra para venda. Assim, não se espera menos da escola do que a excelente preparação de seus estudantes para serem inseridos, e, sobretudo, promoverem o desenvolvimento - ou talvez seja inovação o conceito mais coerente à narrativa - do sistema-mundo vigente (Oliveira, 2000).

Diante desse cenário, não há espanto quanto ao protagonismo atribuído pela Folha de São Paulo a Jorge Paulo Lemann e a outros representantes de fundações, como é o caso da empresária Viviane Senna (Mattos, 2020b), no debate a respeito da educação escolar no contexto de pandemia de COVID-19. Como vimos, sob a perspectiva Moderna/colonial, que depende da (re)produção das relações de exploração para a sua sobrevivência, não há dúvidas de que são, de fato, os donos do capital (ou seus gerentes) os mais adequados interlocutores para se discutir os caminhos para a educação.

Como nos outros casos, entretanto, havemos de pontuar que não estamos diante de uma novidade trazida pelo vírus. Há tempos os economistas, as fundações e a iniciativa privada de modo geral têm se apresentado à sociedade como os mais competentes atores para delinear 
um projeto educacional e, nele, um currículo (Freitas, 2018; Gentili e Silva, 1996; Gentili, 2013 e Laval, 2019). O risco que corremos hoje é o de que, frente à crise política e econômica - que aliás já vinha se delineando no Brasil, mas que irá se acirrar a partir da crise sanitária vivenciada hoje -, esses atores a quem o sistema-mundo capitalista serve, passem a ser construídos não apenas como a melhor, mas como a única saída viável para a educação escolar.

\section{Coronavírus e as inflexões anticoloniais}

Se até aqui foram discutidas as relações de subalternização a que os sujeitos Outros têm sido submetidos, nos interessa agora salientar as práticas de resistência e/ou insurgência por eles protagonizadas. Em outras palavras, neste tópico, desenvolvemos o argumento de que aqueles que, a partir da construção da diferença colonial, foram feitos Outros, têm, hoje, no contexto da pandemia de COVID-19, como também o fizeram ao longo da história, insistentemente denunciado a sua completa ausência no projeto Moderno/colonial de sociedade e de educação. Mais do que isto, conforme veremos, eles têm pronunciado e protagonizado formas anticoloniais de existência e de ação as quais, muitas vezes, não estão estampadas em capas de jornais.

Assim, se começamos as campanhas de prevenção à COVID-19 apelando para que as pessoas utilizassem álcool em gel na higienização das mãos ao saírem de suas casas, a realidade que se apresentou levou à mudança da narrativa de modo a solicitar que as mãos fossem constantemente lavadas com água e sabão por toda a população. "Agora sim", pode ter avaliado, em um primeiro momento, o cidadão médio brasileiro, "temos uma medida de alcance universal". Sua surpresa seria, entretanto, a descoberta de que no Brasil cerca de $15 \%$ dos domicílios não têm acesso à rede geral de distribuição de água e de que aproximadamente $34 \%$ das casas não dispõem de acesso à rede geral de esgoto sanitário (Brasil, 2018b). De modo semelhante o "fique em casa" - que, não raro, resultou na romantização da quarentena pela parcela privilegiada da população -, dadas a enormes desigualdades sociais amargadas por nossa sociedade, bem como a precarização dos direitos trabalhistas e previdenciários, teve que ser substituído pela expressão "se puder, fique em casa".

Nesse sentido, a existência resistente desses coletivos provocou, ao longo da história, e também no contexto desta crise sanitária, uma importante inflexão no que diz respeito às representações hegemônicas a eles atribuídas. No lugar de "sujeitos da falta", no âmbito da pandemia, os históricos processos de subalternização a que foram submetidos são evidenciados, demonstrando que eles são, na verdade, "sujeitos de direitos negados".

No que diz respeito ao anúncio (Freire, 1996) de modos alternativos de existência, contra o neoliberalismo - hegemônica matriz orientadora do Estado Moderno/colonial contemporâneo em que há a primazia do mercado, do indivíduo e da competição (Laval, 2019) - as ações coletivas, a solidariedade e, portanto, o comunitarismo insurgem no enfrentamento das questões decorrentes do alastramento do novo vírus. E aqui estamos nos 
referindo às inúmeras ações protagonizadas, durante a pandemia, pela população LGBTQIA+, indígena, camponesa e pelas pessoas que residem nas periferias da cidade.

Nessa perspectiva, no tempo presente, temos testemunhado os moradores de favelas brasileiras se organizando para criar formas efetivas de combate ao coronavírus, tendo como referência a sua realidade. Comitês populares têm sido criados para o acompanhamento dos moradores que pertencem ao grupo de risco e, assim, para realizar suas compras, fornecer material de proteção e, claro, acompanhar o seu quadro de saúde. Estes comitês também têm cadastrado famílias que se encontram em situações financeiras mais vulneráveis e criado formas de distribuição de cestas básicas e/ou de refeições.

O projeto Serrão sem Corona ${ }^{5}$, iniciativa dos moradores do Aglomerado da Serra, a terceira maior favela do Brasil, localizada em Belo Horizonte, por exemplo, envolveu, de forma voluntária e autônoma, produtoras/es culturais, professoras/es, ativistas, associações, artistas, empreendedoras/es, conselheiras/os tutelares, comerciantes, moradoras e moradores, buscando conter a disseminação do vírus nas oitos vilas que compõem o Aglomerado. A iniciativa se constituiu, conforme definido pelo coletivo, em uma rede de apoio que buscou garantir a acessibilidade a informações a respeito da pandemia pelos moradores; assegurar seus acesso à alimentação básica e a materiais de higiene; além de fomentar a conscientização da comunidade acerca da necessidade de isolamento social ${ }^{6}$.

Além de arrecadarem e distribuírem alimentos e materiais de limpeza e higiene, o Serrão sem Corona também construiu um projeto de distribuição de 2.000 marmitas por dia, durante 40 dias, iniciativa que foi viabilizada pela verba arrecadada na live do rapper Djonga e de outras parcerias. Em decorrência desta ação a rede de apoio gerou empregos para quem foi afetado pela pandemia. São dez cozinheiras e uma grande equipe de logística e distribuição das marmitas, totalizando 75 pessoas moradoras do Aglomerado empregadas.

No campo cultural, o grupo Lá da Favelinha ${ }^{7}$, também com sede na Serra, tem realizado ações que visam a mobilização da juventude negra e periférica. São estes os casos das aulas online de dança e da Batalha de Passinho Virtual, realizado no segundo semestre de 2020.

Também a Central Única de Favelas do Rio de Janeiro (CUFA) vem desenvolvendo diversas ações junto às pessoas moradoras de favelas e que foram afetadas pela pandemia. Por meio de parcerias, sob a hashtag \#cufacontracoronavírus ${ }^{8}$, a organização têm realizado doação de máscaras, testes de COVID-19 e alimentos, além de repassar recursos para esta população.

O programa Mães da Favela, por exemplo, se propõe à arrecadação de fundos que possibilitam tanto a compra e a doação de cestas básicas, quanto o repasse do valor correspondente a elas para as mulheres mães moradoras das mais de 5.000 favelas espalhadas pelo Brasil. Recentemente, sob o título Mães da Favela ON, o projeto assumiu uma nova frente de atuação cujo objetivo é possibilitar a retomada das atividades econômicas afetadas pela COVID-19 nas favelas brasileiras. A estratégia empregada é a democratização do acesso digital buscando conectar, até julho de 2021, dois milhões de mães que vivem na periferia. Para tanto, serão instalados pontos de WiFi gratuito em 150 complexos de favela, além de serem distribuídos 500 mil chips de celular para essas mulheres. A ação teve início nas 
favelas da Rocinha (RJ), Brasilândia (SP) e Heliópolis (SP). Nos próximos meses, o projeto pretende alcançar os 26 estados, além do Distrito Federal.

Ações semelhantes a estas estão em vigência em todo o Brasil mostrando que esses Outros sabem se organizar em exercício de autogestão quando o Estado não cumpre com a sua responsabilidade. Muitos aprendizados e práticas educativas emancipatórias estão sendo gestadas nestas experienciais radicais que confrontam as políticas de exclusão do Estado brasileiro com práticas solidárias e comunitárias que emergem das periferias, tendo os movimentos sociais como sujeitos.

No âmbito da educação formal, muitas escolas têm construído experiências educativas que rompem com o modelo de currículo conteudista e tecnicista que tenta se impor como política educacional nesses tempos de coronavírus. Práticas educativas que se centram nos sujeitos e não nos conteúdos, que se preocupam com a vida dos estudantes e de suas famílias e não apenas com a "matéria a ser vencida" para cumprir as 800 horas letivas (Brasil, 1996) vêm sendo gestadas em várias experiências escolares.

A escola, para muitas crianças e adolescentes, é, além de um contexto de aprendizagem dos saberes tradicionais, um espaço, por excelência, de socialização e de cuidado. Muitas famílias contam com a merenda escolar para a sobrevivência de seus filhos; muitos jovens têm na escola um dos poucos espaços de encontro e troca de experiências. Nessa perspectiva, a instituição escolar, para esses sujeitos Outros, que têm seus direitos negados sistematicamente, pode e deve ser lugar de resistência, de emancipação e de transformação social.

Em consonância a esta perspectiva, no contexto da pandemia de COVID-19, temos testemunhado inúmeras experiências de escolas públicas de Educação Básica construindo canais de interação com os estudantes e suas famílias e buscando compor uma Rede de Apoio e Proteção Social. Em Belo Horizonte, por exemplo, a Escola Municipal Paulo Mendes Campos $^{9}$, instituição que atende estudantes dos anos finais do Ensino Fundamental, criou o material virtual Caderno Mais - é tudo em casa, como um espaço de diálogo e construção de aprendizagens "com" os estudantes e não "para" eles. O Caderno é acompanhado de um vídeo, por meio do qual os professores enviam mensagens para os estudantes e os incentivam a se engajar na proposta que tem seções como: Alô Comunidade!; Racha Cuca; Gira Girô; Você tem fome de quê; entre outras.

Já a Escola Municipal Paulo Freire ${ }^{10}$, também na capital mineira, organizou cestas básicas para as famílias mais necessitadas, com produtos da horta escolar e de doações recebidas. A instituição começou também a monitorar na comunidade aquelas famílias que participavam do programa de Educação Integral e que contavam com a escola para assegurar a alimentação das crianças e jovens. Além disso, canais de comunicação por meio do Whatsapp e do Facebook foram potencializados e faixas foram colocadas no entorno da escola, incentivando as famílias a se comunicarem com os educadores e se colocando à disposição para atender quem estava passando por dificuldades. A troca de mensagens nos grupos foi incentivada também como forma de expressão e de criatividade, buscando criar, ainda mais, um sentimento de grupo, de coletivo entre os estudantes, professores e agentes culturais. 
Destacamos também a experiência da escola pública Polo de Educação Integrada de Ilhabela (PEII) ${ }^{11}$ que atende 124 crianças dos anos iniciais do Ensino Fundamental no bairro de Itaquanduba na cidade do litoral norte do estado de São Paulo. Em meio à pandemia, a instituição tem investido em ações de aproximação com a comunidade, na escuta ativa das famílias e no desenvolvimento de um projeto de economia solidária realizado junto a moradores do bairro onde a escola se localiza.

Uma importante ação protagonizada pelo PEII em meio à pandemia foi a confecção de um jornal de circulação local e interativo chamado Sankofa. O jornal é de construção coletiva e busca um diálogo entre a escola e a comunidade escolar. Em sua primeira edição o periódico registrou histórias dos moradores, das ruas e dos becos do bairro, contribuindo para o resgate da identidade local. O Sankofa também se propõe a promover a reflexão sobre temas contemporâneos como racismo e feminismo, além de apresentar sugestões de atividades recreativas - indicação de receitas, filmes e livros - para que as crianças desenvolvam junto a seus familiares.

Como estas, muitas escolas no Brasil têm se tornado um centro catalizador de encontro e troca, de apoio e solidariedade, de cultura e criação, gerando novas práticas educativas, mais decoloniais na medida em que confrontam e questionam as propostas de aulas remotas centradas em materiais "à prova de professores e de alunos", um verdadeiro repositório de conteúdos vazios e descontextualizados. Em detrimento da concepção hegemônica de educação a que vimos discutindo, essas experiências têm revelado a força e a importância da educação escolar como espaço de vida e de cultura, mesmo em tempos de isolamento social.

\section{Considerações finais}

O trágico contexto da pandemia nos colocou diante de uma enorme encruzilhada. Devemos, enquanto sociedade, decidir se prosseguiremos em um caminho cuja exclusão é a mais profunda marca e que se revela sem qualquer sutileza, ou se, ao contrário, nos disponibilizaremos a legitimar e a construir, com os Outros, projetos de sociedade não orientados pela segregadora matriz Moderna/colonial.

Essa mesma interrogação se coloca para campo educacional neste momento histórico. Temos a possibilidade de observar cada uma das questões com as quais a educação escolar tem sido confrontada como espécies de sintomas da pandemia a serem eficazmente combatidos. E, se assim for, certamente, as mais óbvias soluções apresentadas serão a disponibilização de equipamentos para que crianças e jovens possam acessar os conteúdos escolares, a democratização do acesso à internet, a elaboração de novos materiais e, quem sabe, os mais ousados, não passem até a pensar em cursos de formação para que os familiares se tornem espécies de tutores das crianças e jovens confinados. Sob essa perspectiva de nova "normalidade" a nossa sociedade segregada e por nós naturalizada será muito pouco ou quase nada interrogada.

A outra possibilidade de caminho para o campo educacional a partir da vivência da pandemia, sem dúvidas mais desafiadora do que a primeira, será a reivindicação dos direitos 
negados, mas a partir da contestação do histórico vínculo entre educação escolar e o projeto colonial. Isto implicará, claro, na qualificação da infraestrutura e dos profissionais da educação, mas, sobretudo, na realização de incômodas e desestabilizadoras interrogações entre as quais destacamos: É, de fato, com este modelo de sociedade que produz doenças que, por vias diretas ou indiretas, exterminam a humanidade que a escola deseja se alinhar? Estaria o valor da educação escolar, de maneira imutável, condicionado ao atendimento das demandas da sociedade capitalista excludente e genocida? A racionalidade Moderna/colonial que desfruta de hegemonia nos ambientes educativos tem realmente se apresentado como suficiente e adequada para a produção de uma sociedade, se não emancipada, menos desigual? Não poderia a escola constituir-se num ambiente de imaginação de futuros Outros não segregados?

Sendo essa a opção feita, estaremos diante da desafiadora tarefa de desaprendizagem colonial, já que, conforme nos lembra Walsh (2009), para Fanon (1968, p. 62), "la descolonización es una forma de (des)aprendizaje: desaprender todo lo impuesto y assumido por la colonización y deshumanización para reaprender a ser mujeres e hombres". A boa notícia é que, como vimos, os sujeitos Outros têm, insistentemente, nos apontado caminhos alternativos. Oxalá a experimentação da pandemia provoque em nós a disposição de desaprender com aqueles que não temem imaginar e produzir futuros libertos das relações coloniais.

\section{Notas}

1. A designação "Outro" será utilizada de maneira recorrente neste texto em referência à noção de diferença colonial formulada por Walter Mignolo (2003) e que constitui-se na transformação, no âmbito do projeto colonial, das diferenças culturais em valores e hierarquias, orientando, assim, as relações de subalternização. Se, no colonialismo, o "Outro" é tomado como primitivo, excêntrico e até inumano, aqui, em consonância ao pensamento anticolonial, mobilizamos o termo de maneira afirmativa e, assim, em referência às diferentes formas de existência, conhecimento e organização societária em detrimento do universalismo colonial difundido no âmbito do projeto de Modernidade.

2. Cf. Charleux (2020).

3. A respeito das distinções entre as modalidades de educação não presencial, cf. Arruda (2020).

4. Estas disciplinas tornaram-se não obrigatórias no Ensino Médio por meio de Medida Provisória 746 (Brasil, 2016) do então presidente Michel Temer. Após a reformulação do texto, os conteúdos voltam a compor, a partir do núcleo de "Ciências Humanas e Sociais Aplicadas" da Base Nacional Comum Curricular (Brasil, 2017) o currículo desta etapa da Educação Básica, ficando, entretanto, a carga horária destinada a eles a cargo dos Estados e Municípios.

5. Sobre o projeto Serrão sem corona, cf. https://www.facebook.com/serraosemcorona/.

6. Informações divulgadas pelo coletivo em: https://evoe.cc/serraosemcorona.

7. Centro Cultural independente que tem a missão de incentivar o empreendedorismo criativo e comunitário e promover a educação, cultura e o desenvolvimento humano, principalmente, de crianças e jovens do Aglomerado da Serra, em Belo Horizonte. Informações divulgadas em: https://evoe.cc/ladafavelinha.

8. Sobre o projeto Mães da favela, cf. https://www.maesdafavela.com.br/.

9. Sobre Caderno Mais - é tudo em casa, cf. https://pt-br.facebook.com/empmcoficial/.

10. Sobre as ações realizadas pela Escola Municipal Paulo Freire, cf. https://pt-br.facebook.com/escolapaulofreireembu/.

11. Sobre as ações realizadas pelo Polo de Educação Integrada de Ilhabela, cf. https://www.reporteronlinelitoral.com.br/press/2020/07/04/polo-de-educacao-integrada-de-ilhabela-lanca-jornal/ 


\section{Referências}

ARROYO, Miguel Gonzales. Educação e exclusão da cidadania. In: BUFFA, Ester; ARROYO, Miguel Gonzales; NOSELLA, Paolo. Educação e Cidadania: quem educa o cidadão? São Paulo: Cortez, 2010.

ARRUDA, Eucídio Pimenta. Educação remota emergencial: elementos para políticas públicas na educação brasileira em tempos de Covid-19. Revista Em Rede, Porto Alegre, v. 7, 2020. Disponível em: https://www.aunirede.org.br/revista/index.php/emrede/article/view/621. Acesso em: 21 jun. 2020.

BRASIL. Câmara dos Deputados. Lei 12.061 de 27 de outubro de 2009. Altera o inciso II do art. 4o e o inciso VI do art. 10 da Lei no 9.394, de 20 de dezembro de 1996, para assegurar o acesso de todos os interessados ao ensino médio público. Brasília: Câmara dos Deputados, 2009.

BRASIL. Ministério da Educação. Base Nacional Comum Curricular: terceira versão. Brasília: Ministério da Educação, 2017.

BRASIL. IBGE. Pesquisa Nacional por Amostra de Domicílios Contínua. Educação. Brasília: IBGE, 2018 a. Disponível em: https://biblioteca.ibge.gov.br/visualizacao/livros/liv101657_informativo.pdf. Acesso em: 09 mai. 2020.

BRASIL. IBGE. Pesquisa Nacional por amostra de domicílios: Características Gerais dos Domicílios e dos Moradores. Brasília: IBGE, 2018b. Disponível em: https://biblioteca.ibge.gov.br/index.php/ bibliotecacatalogo?view=detalhes\&id=2101654. Acesso em: 11 jun. 2020.

BRASIL. Ministério da Educação. Lei de no 9.394 de 20 de dezembro de 1996. Estabelece as diretrizes e bases da educação nacional. Brasília: Ministério da Educação, 1996.

BRASIL. Ministério da Saúde. Brasil confirma primeiro caso da doença. Agência saúde. Brasília: Ministério da Saúde, 2020a. Disponível em: https://www.saude.gov.br/noticias/agencia-saude/46435-brasil-confirmaprimeiro-caso-de-novo-coronavirus. Acesso em: 17 mai. 2020.

BRASIL. [Constituição (1934)]. Constituição da República dos Estados Unidos do Brasil. Brasília: Presidência da [2020b]. República, Disponível em: http://www.planalto.gov.br/ccivil_03/constituicao/constituicao34.htm. Acesso em: 22 jul. 2020.

BRASIL. Presidência da república. Medida Provisória 746 de 22 de setembro de 2016. Institui a Política de Fomento à Implementação de Escolas de Ensino Médio em Tempo Integral, altera a Lei no 9.394, de 20 de dezembro de 1996, que estabelece as diretrizes e bases da educação nacional, e a Lei $n^{\circ} 11.494$ de 20 de junho 2007, que regulamenta o Fundo de Manutenção e Desenvolvimento da Educação Básica e de Valorização dos Profissionais da Educação, e dá outras providências. Brasil, 2016.

CHARLEAUX, João Paulo. Acusação contra os EUA de prática de 'pirataria moderna'. Nexo Jornal, São Paulo, 02 abr. 2020. Expresso, s.p. Disponível em: https://www.nexojornal.com.br/expresso/2020/04/07/Aacusa \%C3\%A7\%C3\%A3o-contra-os-EUA-de-pr\%C3\%A1tica-de-\%E2\%80\%98piratariamoderna\%E2\%80\%99. Acesso em: 14 de mai. 2020.

COSTA, Fernanda. Morte de trabalhadora doméstica por coronavírus escancara falta de políticas para proteger a classe. UFRGS - Jornal da Universidade, Rio Grande do Sul, 26 mar. 2020. Extra Coronavírus, s.p. Disponível em https://www.ufrgs.br/jornal/morte-de-trabal\%20adora-domestica-por-coronavirusescancara-falta-de-politicas-para-proteger-a-classe/. Acesso em: 11 jun. 2020.

DAVIS, Angela. Mulheres, cultura e política. São Paulo: Boitempo, 2016.

DINIZ, Ana Maria. As lições e os legados da pandemia para a educação. Estado de S. Paulo, São Paulo, 31 jul. 2020. Blogs, s.p. Disponível em: https://educacao.estadao.com.br/blogs/ana-maria-diniz/as-licoes-e-oslegados-da-pandemia-para-a-educacao/. Acesso em: 23 out. 2020. 
DOLZAN, Márcio. Covid fará desigualdade aumentar na educação, diz estudo da FGV. Estado de S. Paulo, São Paulo, 20 out. 2020. .Edu, s.p. Disponível em: https://educacao.estadao.com.br/noticias/geral,covidfara-desigualdade-aumentar-na-educacao-diz-estudo-da-fgv,70003482467. Acesso em: 25 out. 2020.

ESTRELA, Fernanda Matheus. Pandemia da Covid 19: refletindo as vulnerabilidades a luz do gênero, raça e classe. Ciênc. saúde coletiva, Rio de Janeiro , v. 25, n. 9, p. 3431-3436, Sept. 2020 . Disponível em: http://www.scielo.br/scielo.php?script=sci_arttext\&pid=S141381232020000903431\&lng=en\&nrm=iso. Acesso em 27 out. 2020.

FANON, Frantz. Os condenados da terra. São Paulo: Civilização Brasileira, 1968.

FONSECA, Thais Nivia de Lima e. "Segundo a qualidade de suas pessoas e fazenda": estratégias educativas na sociedade mineira colonial. Varia História, Belo Horizonte, v. 22, n. 35, p. 175-188, 2006. Disponível em: http://www.scielo.br/scielo.php?script=sci_arttext\&pid=S0104-87752006000100010\&lng=en\&nrm=iso . Acesso em: 26 out. 2020.

FREIRE, Paulo. Pedagogia da autonomia: saberes necessários à prática educativa. 1 ed., São Paulo: Paz e Terra, 1996.

FREITAS, Luiz Carlos de. A reforma empresarial da educação: nova direita, velhas ideias. 1. ed. São Paulo: Editora Expressão Popular, 2018. v. 1. 160p .

GENTILI, Pablo; SILVA, Tomaz Tadeu da (Org.) . Escola S. A.: Quem ganha equem perde no mercado educacional do neoliberalismo. Brasília: CNTE, 1996. 188p .

GENTILI, Pablo. Pedagogia da exclusão: crítica ao neoliberalismo em educação. 19. ed. Petrópolis, Rio de Janeiro: Vozes, 2013. 303p.

GOMES, Rafael. Como a pandemia está revolucionando o uso da tecnologia na educação. . Estado de S. Paulo, São Paulo, 04 jul. 2020. Blogs, s.p. Disponível em: https://politica.estadao.com.br/blogs/faustomacedo/como-a-pandemia-esta-revolucionando-o-uso-da-tecnologia-na-educacao/. Acesso em: 23 de out. de 2020.

IDOETA, Paula Adamo. 'Sem wi-fi': pandemia cria novo símbolo de desigualdade na educação. BBC News, São Paulo, 03 out. 2020. Brasil, s.p. Disponível em: https://www.bbc.com/portuguese/brasil-54380828. Acesso em: 26 out. 2020.

INSTITUTO NACIONAL DE ESTUDOS E PESQUISAS EDUCACIONAIS ANÍSIO TEIXEIRA. Censo da Educação Superior: Sinopse Estatística - 2018. Disponível em: http://inep.gov.br/sinopses-estatisticas-daeducacao-superior. Acesso em: 03 jun. 2020.

LAVAL, Christian. Escola não é empresa. São Paulo: Boitempo, 2019

MARTINEZ-VARGAS, Ivan. Lemann dará maior ênfase a ensino virtual em suas fundações. Folha de $\mathbf{S}$. Paulo, São Paulo, 14 mai.2020. Mercado, n.p. Disponível em: https://www1.folha.uol.com.br/mercado/ 2020/05/lemann-dara-maior-enfase-a-ensino-virtual-em-suas-fundacoes.shtml. Acesso em: 14 mai. 2020.

MARQUES, Emanuele Souza. A violência contra mulheres, crianças e adolescentes em tempos de pandemia pela COVID-19: panorama, motivações e formas de enfrentamento. Cad. Saúde Pública, Rio de Janeiro, v. 36, n. 4, 2020 . Disponível em: http://www.scielo.br/scielo.php?script=sci_arttext\&pid=S0102311X2020000400505\&lng=en\&nrm=iso. Acesso em 17 mai. 2020.

MATTOS, Laura. As lições da quarentena para a educação. Folha de S. Paulo, São Paulo, 14 mai.2020a. Colunas e blogs, n. p. Disponível em: https://www1.folha.uol.com.br/colunas/laura-mattos/2020/05/aslicoes-da-quarentena-para-a-educacao.shtml. Acesso em: 14 mai. 2020.

MATTOS, Laura. Está claro que a reabertura das escolas não agrava a pandemia, diz Viviane Senna. Folha de S. Paulo, São Paulo, 16 set. 2020b. Educação, n. p. Disponível em: https://www1.folha.uol.com.br/educacao/2020/09/esta-claro-que-a-reabertura-das-escolas-nao-agrava-apandemia-diz-viviane-senna.shtml >. Acesso em: 26 de out. de 2020.

MIGNOLO, Walter. Histórias locais/projetos globais. Belo Horizonte: UFMG, 2003. 
NÚCLEO DE OPERAÇÃO E INTELIGÊNCIA EM SAÚDE. Nota técnica nº 11 . Análise socioeconômica da taxa de letalidade da COVID-19 no Brasil. Disponível em: https://ponte.org/wpcontent/uploads/2020/05/NT11-An\%C3\%A1lise-descritiva-dos-casos-de-COVID-19.pdf. Acesso em: 11 jun. 2020.

OLIVEIRA, Dalila A. Educação básica: gestão do trabalho e da pobreza. Petrópolis: Vozes, 2000.

PINHO, Ângela. Menos de metade dos alunos da rede estadual de SP acessa ensino online na quarentena. Folha de S. Paulo, São Paulo, 14 mai.2020. Educação, s.p. Disponível em: https://www1.folha.uol.com.br/educacao/2020/05/menos-de-metade-dos-alunos-da-rede-estadual-de-spacessa-ensino-online-na-quarentena.shtml. Acesso em: 14 mai. 2020.

PONTES, Ana Lucia; ALARCON, Daniela Fernandes; KAINGANG, Joziléia Daniza; SANTOS, Ricardo Ventura. Vulnerabilidades, impactos e o enfrentamento ao Covid-19 no contexto dos povos indígenas: reflexões para a ação. Observatório Covid-19 Fiocruz, 5p., 2020.

SANTOS, Boaventura de Sousa. A cruel pedagogia do vírus. São Paulo: Boitempo, 2020.

SANTOS, Boaventura de Sousa; MENESES, Maria Paula [orgs.]. Epistemologias do Sul. São Paulo: Cortez, 2010.

SANTOS, Boaventura de Sousa. Para além do pensamento abissal: das linhas globais a uma ecologia de saberes. Novos Estudos CEBRAP, São Paulo, n. 79, p. 71-94, nov. 2007. Disponível em: https://www.scielo.br/scielo.php?script=sci_arttext\&pid=S0101-33002007000300004\&lng=en\&nrm=iso. Acesso em: 03 jun. 2020.

SAVIANI, Dermeval. Educação escolar, currículo e sociedade: o problema da Base Nacional Comum Curricular. Movimento - Revista de Educação, Rio de Janeiro, v.3, n. 4. p.54-84. Disponível em: https://periodicos.uff.br/revistamovimento/article/view/32575/18710. Acesso em: 24 out. 2020.

SOARES, Rossieli. Alunos de hoje serão formados em mundo revirado pela pandemia. Folha de S. Paulo, São Paulo, 12 jun. 2020. Opinião, s.p. Disponível em: https://www1.folha.uol.com.br/educacao/2020/06/alunosde-hoje-serao-formados-em-mundo-revirado-pela-pandemia.shtml?origin=folha. Acesso em: 25 out. 2020.

SOUZA, Jessé. (Não)Reconhecimento e subcidadania, ou o que é "ser gente"? Lua Nova, São Paulo, n. 59, p. 51-73, 2003. Disponível em: https://www.scielo.br/scielo.php?script=sci_arttext\&pid=S010264452003000200003\&lng=en\&nrm=iso. Acesso em: 13 nov. 2016.

THINK OLGA. Mulheres em Tempos de Pandemia: os agravantes de desigualdades, os catalisadores de mudança. Disponível em: https://thinkolga.squarespace.com/. Acesso em: 03 jun. 2020.

VEIGA, Cynthia Greive. História da Educação. 1. ed., São Paulo: Ática, 2007. 328 p.

WALLERSTEIN, Immanuel. O sistema mundial moderno: a agricultura capitalista e as origens da economiamundo europeia no século XVI. Porto: Afrontamentos, v. I, 1974.

WALSH, Catherine. Interculturalidad crítica y pedagogia de-colonial: apuestas (des)de in-surgir, re-existir e re-vivir. Educação on-line. Departamento de Educação PUC-Rio, 2009. Disponível em: http://catherinewalsh.blogspot.com/. Acesso em: 11 jun. 2020.

XIMENES, Salomão.; CÁSSIO, Fernando.; PELLANDA, Andressa.; BRAZ, Marina. A discriminação do ensino não presencial em tempos de pandemia. Nexo Jornal, São Paulo, 16 jun. 2020. Debate, sp. Disponível em: https://www.nexojornal.com.br/ensaio/debate/2020/A-discrimina\%C3\%A7\%C3\%A3o-noensino-n\%C3\%A3o-presencial-em-tempos-de-pandemia. Acesso em: 25 out. 2020. 


\section{Correspondência}

Lúcia Helena Alvarez Leite: É professora associada da Faculdade de Educação da Universidade Federal de Minas Gerais. Faz parte do Programa de Pós Graduação da FAE/UFMG, integrando a linha: Educação, Cultura, Movimentos Sociais e Ações Coletivas. Pesquisa e publica na área de educação, com ênfase em Educação e Movimentos Sociais, atuando principalmente nos seguintes campos de investigação: educação decolonial, educação indígena e educação integral. Coordena o grupo de pesquisa e extensão - TEIA (Territórios, Educação Integral e cidadaniA) e o Observatório da Educação Integral (2012-2017), ambos da FAE/UFMG.

E-mail: lualvarezleite@ gmail.com

Bárbara Bruna Moreira Ramalho: É Doutora e Mestra em Educação e Pedagoga pela Faculdade de Educação $(\mathrm{FaE})$ da Universidade Federal de Minas Gerais (UFMG). É docente dos $1^{\circ}$ e $2^{\circ}$ ciclos do Ensino Fundamental na Rede Municipal de Educação de Belo Horizonte, tendo também atuado na gestão municipal do Programa Escola Integrada. Pesquisa e publica na área de educação atuando principalmente nos seguintes temas: educação e pobreza; educação e interseccionalidade; educação anticolonial; e educação integral. É membro do núcleo de ensino, pesquisa e extensão Territórios Educação Integral e Cidadania (TEIA) da FaE/UFMG.

E-mail: bbramalho@gmail.com

Paulo Felipe Lopes de Carvalho: É Doutor e Mestre em Educação pela Faculdade de Educação-FaE da Universidade Federal de Minas Gerais - UFMG. É professor de geografia desde 2012 - Ensino Fundamental, Ensino Médio e Educação de Jovens e Adultos da Rede Estadual de Educação do Estado de Minas Gerais. Integra o grupo TEIA - Territórios, Educação Integral e CidadaniA da FaE-UFMG. Tem trabalhos e publicações diversas que tangenciam os seguintes temas: Educação Integral/Integrada; Espaços e Territórios Educativos; Educação e Ações Coletivas; Diversidade e Educação, Educação e Movimentos Sociais.

E-mail: pfelipegeo@gmail.com

Texto publicado em Currículo sem Fronteiras com autorização dos autores 